\title{
Resource Development Opportunities for the Association of Leadership Educators: Phase One
}

\author{
Donnette J. Noble \\ Assistant Professor of Organizational Leadership \\ Roosevelt University \\ Evelyn T. Stone College of Professional Studies \\ Chicago, IL 60603 \\ Lyna Matesi \\ Assistant Professor of Management \\ School of Business \& Economics \\ University of Wisconsin-Stevens Point \\ Jennifer Moss Breen \\ Associate Professor - Interdisciplinary Ed.D. Program in Leadership \\ Creighton University \\ Omaha NE 68178 \\ Robin Peiter Horstmeier \\ Founder and Owner - Horstmeier Consulting LLC \\ Associate Teaching Professor \\ University of Missouri-Columbia \\ Dennis M. Anderson \\ Distinguished Professor - Leadership Studies Department \\ Marshall University \\ College of Education and Professional Development \\ South Charleston, WV 25303 \\ Stuart Allen \\ Associate Professor of Organizational Leadership \\ Robert Morris University \\ School of Communication and Information Systems \\ Moon Township, PA 15108

\section{Leslie Pedigo} \\ University of Kentucky \\ Lexington, KY 40526
}


Journal of Leadership Education DOI: 10.12806/V15/I1/A4 Volume 15 Issue 1 Application

\begin{abstract}
This application brief shares Phase One of an action research project for the Association of Leadership Educators. This project demonstrates how a member-based association can successfully engage its members in terms of identifying needs, defining strategic priorities, and detecting resource development opportunities. This body of work has various implications for leadership and leadership education and provides a model that other associations can replicate to engage in resource development.

A brief history of the association's first 25 years since its inception is provided in this brief and the work of the Resource Development Committee is presented. The findings from two focus group sessions conducted during the 2014 annual conference are highlighted and the paper closes with a discussion of how the Resource Development Committee can, through specific initiatives, support the association's wellbeing and strategic direction. By sharing the rationale behind the Association of Leadership Educators board of directors' decision to invest in a resource development strategy, other association leaders can access and implement a similar action plan to generate additional revenue which, in turn, can be used to enhance association membership services.
\end{abstract}

\title{
Introduction
}

Voluntary associations have been particularly useful in furthering the shared interests of professional and educational groups (Hall, 2006) and leading them can be very rewarding. Nevertheless, voluntary associations can face challenges that include meeting long-term goals and individual member's needs, setting priorities in the face of competing interests, and coordinating member volunteers (Harris, 1998). According to Renz (2004), a common challenge for voluntary associations is meeting the association's strategic funding needs; however, engaging a development committee can significantly strengthen this effort. Development committees typically work with an association's staff and board members to raise funds to further the strategic plan of an organization.

The Association of Leadership Educators (ALE), a voluntary association, took root in 1990 for the purpose of providing leadership professionals with a forum to share ideas and begin bridging the gaps among leadership education, theory, research, and practice. On ALE's twentyfifth anniversary, the membership totaled nearly 300 and represented a diverse blend of public and private entities, institutes of higher education, consulting firms, publishers, and other agencies and organizations.

The mission of ALE is to "strengthen and sustain the expertise of professional leadership educators" and its vision is to be a "...leading resource for the exchange and development of quality ideas, scholarship, and practice that impacts the field of leadership education...through an inclusive and engaging community of dynamic leadership educators..." ("About ALE", 2015).

In fulfillment of its mission and vision, ALE connects with its members via a monthly newsletter, The Fast Forum, and a quarterly publication, The Forum. ALE has held annual 
conferences since 1991 and, in 2002 ALE began publishing the Journal of Leadership Education (JOLE). ALE is also a driving force behind the National Leadership Education Research Agenda 2013-2018 (Andenoro, Allen, Haber-Curran, Jenkins, Sowcik, Dugan, \& Osteen, 2013) which is a collaborative project developed in 2011 that actualizes the essence of ALE by identifying research priorities that can guide applied scholarship that contributes to the development of future leaders.

ALE has established itself as a premier professional leadership association and is fiscally solvent. However, like most volunteer organizations, the association has a few challenges. These challenges include: (a) how to attract and retain new members; (b) how to add value to members' experiences and meet the mission and the vision of the association more fully; (c) how to increase revenue and open new revenue streams that sustain and serve members; and (d) in general, how to make a relevant and successful organization even better.

The ALE board of directors have discussed a number of strategies to enhance the association such as: (a) increasing support for ALE's inclusive community; (b) creating more opportunities for member engagement; (c) enhancing online engagement; (d) boosting the advancement of the scholarship and practice of leadership educators; (e) continuing to deliver high quality and innovative conferences; and (f) investing in the future of the association through collaborative and strategic relationships. While all of these strategies are of value to the association, they require human and financial capital to operationalize. In 2013, a new group of people were organized to serve on the Resource Development Committee (RDC). The RDC is charged with the responsibility of creating an actionable plan for developing resources for ALE.

\section{Phase One}

The RDC spent one year researching and developing a Strategic Fundraising Plan that centers on three initiatives that are grounded in strategic philanthropic support (Frumkin, 2006): (a) scholarship and award endowment; (b) partnership development; and (c) webinar sponsorship. The RDC has recommended that ALE focus its attention on the targeting companies, foundations, and organizations whose purposes are collaboratively advanced by their affiliation with the association. It is expected that these initiatives will yield new revenue streams once implemented.

ALE's quest for strategic philanthropic support will enable it to more fully recognize its mission. Through thoughtful collaboration, ALE and its partners can develop mutually beneficial relationships that contribute meaningfully to support the needs and values of involved entities. This support will allow ALE to: (a) create new and enhanced value for ALE and its service to the field of leadership education; (b) promote break-through research that addresses complex issues relative to the field of leadership education; and (c) leverage the association's spheres of influence. For ALE, strategic philanthropic endeavors will facilitate the association's efforts to develop programs and services not otherwise possible.

The first initiative, scholarship and award endowment, would provide graduate students enrolled in leadership studies programs at accredited institutions with the financial support necessary to attend ALE's annual conferences. Through this effort ALE clearly demonstrates its 
dedication to emerging leaders and scholars by enriching the experiences of students and helping them to build their professional networks.

The second initiative, partnership development, will allow ALE to broaden its network and establish new partnerships with a variety of entities interested in the study and application of leadership. Such partnerships can increase membership, increase conference participation, and enhance the conference program. By growing the membership and expanding the conference, ALE will expose members and participants to additional leadership scholarship and practices through the engagement of a broader base of leadership experts.

Association created, hosted, and maintained webinars (the third initiative) creates a unique avenue for ALE to reach its target audience quickly and efficiently. These webinars will facilitate the sharing of information and will optimize the utilization of interesting and relevant content to its membership.

The RDC encouraged ALE to engage in action research approaches to gauge associationwide interest and support for the initiatives. Action research is a participatory and democratic process concerned with bringing together action, reflection, theory, and practice in the pursuit of practical knowledge and solutions (Reason \& Bradbury, 2001). Action research typically follows four basic stages: (a) finding a starting point; (b) clarifying the situation; (c) developing action strategies and putting them into practice; and (d) generating analyses and theories (Altrichter, Feldman, Posch, \& Somekh, 1993, p. 8). The action research project developed for ALE by the RDC addresses the first three of these four stages.

\section{Methodology}

The RDC hosted two 60-minute focus groups during the 2014 ALE conference in San Antonio, Texas. Focus groups center on a "carefully planned series of discussions to obtain perceptions on a defined area of interest in a permissive, non-threatening environment" (Krueger \& Casey, 2009, p. 2) and are frequently used to evaluate organizations or programs (GrudensSchuck, Allen, \& Larson, 2004; Linville, Lambert-Shute, Fruhauf, \& Piercy, 2003). Focus groups are one of the data collection methods available to action researchers, along with surveys and interviews (Chiu, 2003). ALE conference registrants were informed of the opportunity to participate in one of two scheduled focus groups in advance of the conference via email and the dates and times for the each of the focus groups was published in the 2014 conference program.

Participation in the focus groups was voluntary and after informed consent was secured, participants were presented with seven open-ended questions (Table 1) to consider. In addition, participants were provided with a separate document that described the three initiatives that the RDC identified (Scholarship and Award Endowment, Partnership Development, and Webinar Sponsorship). An RDC member facilitated the conversations and two RDC members transcribed participants' comments. The transcripts were shared among RDC members and the discussion responses were then coded to produce a consolidated picture (re-contextualization) of the phenomenon being addressed (Creswell, 1994; Richards \& Morse, 2007; Tesch, 1990). 
Journal of Leadership Education DOI: 10.12806/V15/I1/A4 Volume 15 Issue 1 Application

\begin{tabular}{lll}
\multicolumn{2}{l}{ Table 1: Open-ended Questions Presented to Focus Groups } \\
\hline No. & Topic & Question \\
\hline 1 & Perception_-Personal & What drew you to the Association of Leadership Educators? \\
\hline 2 & Perception_-Professional & $\begin{array}{l}\text { How would you describe the "leadership educator" } \\
\text { profession's perception of ALE? }\end{array}$ \\
\hline 3 & Fundraising_Plan & $\begin{array}{l}\text { What are your reactions to the strategic fundraising } \\
\text { initiatives? }\end{array}$ \\
\hline 4 & Fundraising_-Plan & $\begin{array}{l}\text { How do these strategic fundraising initiatives relate to your } \\
\text { organization's philanthropic interests and priorities? }\end{array}$ \\
\hline 5 & $\begin{array}{l}\text { Fundraising_- } \\
\text { Implementation }\end{array}$ & $\begin{array}{l}\text { How do you suggest attracting voluntary support for these } \\
\text { strategic fundraising initiatives? }\end{array}$ \\
\hline 6 & $\begin{array}{l}\text { Fundraising- } \\
\text { Implementation }\end{array}$ & $\begin{array}{l}\text { What potential challenges to do you see in terms of } \\
\text { implementing these strategic fundraising initiatives? }\end{array}$ \\
\hline 7 & Fundraising-Competition & $\begin{array}{l}\text { When thinking about ALE's most likely donors or } \\
\text { supporters, what organizations or interests is ALE competing } \\
\text { with? }\end{array}$ \\
\hline
\end{tabular}

Overall, the participation in the focus groups was far lower than expected $(n=4)$. The lower participation rates may be due to the timing of the focus groups. Session one occurred on Sunday afternoon between the pre-conference sessions and the opening reception, and session two was scheduled for 7:30 a.m. on the first full day of the conference (Monday) and was in direct competition with other conference events that were occurring prior to the breakfast and the opening plenary. Following the focus groups, ALE conducted a member survey and those responses $(n=98)$ reflect the positions of the focus group participants.

\section{Findings}

Participants' comments and ideas were analyzed and are described below in the order the questions were presented. Additionally, information from the ALE member survey is also presented when particular points can be clarified with the additional information or when the information is reflective of the broader themes noted in this action research project.

Question One. Of the conference attendees participating in the focus group sessions, all but one were newcomers to the conference making the question "What drew you to the Association of Leadership Educators?" particularly relevant. Interestingly, all of the participants were aware of ALE for some time before they attended their first conference. One participant recently published a book and was looking for additional venues to showcase the work. A second participant encountered an ALE board member at an International Leadership Association conference and after the board member shared information about ALE, the participant made the decision to attend the conference in San Antonio. A third participant recently changed professional positions and was specifically looking for organizations that support leadership development. A fourth participant indicated that she learned of ALE while in school but it was not until after graduation and the acceptance of a position in student leadership development at a different school that she decided to attend an ALE conference. According to the ALE member 
survey, more than half of the respondents $(54 \%)$ became aware of the association as the result of a recommendation by either an ALE member or a colleague.

Question Two. When asked to describe the leadership educator profession's perception of ALE, there was unanimity surrounding the notion that ALE is not well known, even in leadership circles. The exception to this, according to participants, is with agriculture-based leadership programs; the scholars and students in this industry are typically aware of the association, but people focusing on leadership in other areas (e.g., organizational, behavioral) are not as likely to know about the association.

While it is true that a number of ALE survey respondents do belong to agriculturefocused associations, such as the Association of Agriculture Educators, the National Association of Extension Agents, and the Association of International Agriculture Extension Educators (among others), ALE members belong to a variety of other associations. Seventy-four percent of the survey respondents also belong to the International Leadership Association, the Academies of Management, and other student development, human resources, arts education, and coaching organizations.

Question Three. When asked for their reactions to the strategic fundraising initiatives (Scholarship and Award Endowment, Partnership Development, and Webinar Sponsorship) developed by the RDC, focus group participants were generally positive with the strongest reaction centered on scholarship.

Participants indicated a strong desire (and need) to support members (and students in particular) at all levels. Participants felt this initiative would have additional benefits in that students who become involved with ALE early in their careers are likely to become members in the long term and, in turn, will be instrumental in recruiting additional members. Similarly, participants indicated desires to offer more discounts to students, support the continuation of mini-grants, support work related to the National Leadership Education Research Agenda, and increase the availability of resources related to scholarship (e.g., methodology, theory development).

Participants also saw partnership opportunities as a viable initiative and one of "huge" opportunity but there is a common concern related to the initiatives. Specifically, participants felt that ALE must do a much better job of marketing itself and selling its story and benefits and, according to participants, a failure to make this case will compromise long-term funding. Interestingly, members indicated that there is value in partnering with other organizations, and many of the 98 survey respondents provided either specific names of entities that they feel would be well served by an ALE partnership (and vice versa) or industries that should be targeted (e.g., colleges and universities and the armed services).

Focus group participants viewed webinars as a valuable and beneficial service to members, academic leaders, and others who want to know more about a particular topic. Offering webinars to non-ALE members was also viewed by participants as a good way to recruit more people to become involved with ALE. Participants felt strongly that ALE needs a "hook" and needs to differentiate itself to establish its value, and it was mentioned that webinars 
may serve that purpose. Focus group participants also recommended offering continuing education credits (CEUs) for webinar attendees.

Survey respondents are in agreement and many suggestions for webinars have been offered, including ground-breaking leadership theories or practices, publishing in academic journals, emotional intelligence, best practices, mentoring, global leadership practices, and newcomer orientation.

Question Four. Connecting ALE's fundraising initiatives with the philanthropic interests and priorities of participants' organizations were viewed as problematic, mainly because ALE is not a large, well-known entity. Participants recommended that ALE be clear about "who" they are and "what" they do. Participants suggested that one way ALE can share its message is to better utilize its website. The majority of survey respondents are not actively engaged in following ALE on Twitter, Facebook, or LinkedIn and have, in essence, confirmed the need for the association to extend its reach digitally and become more effective in this area.

Question Five. In terms of attracting voluntary support for the strategic fundraising initiatives, participants emphasized the need for ALE to capitalize on its networking opportunities to attract voluntary support for each of the initiatives presented. Participants indicated that an emotional investment in ALE is key to solidifying the support the association needs to meet its short-term and long-term goals and objectives. Likewise, a number of respondents indicated on the survey that they think the association, and thereby the fundraising efforts, could be strengthened by having regional or local ALE chapters.

Question Six. Participants supported the identified strategic fundraising initiatives but mentioned that enthusiasm wanes the conferences are over. Participants recommended that ALE leverage a group of "gung ho" volunteers to keep the excitement high and keep the interest in volunteering at peak levels. It was suggested that ALE support collaborative works (e.g., white papers, books) with small stipends and encourage special interest groups to work together to keep people engaged in the association year-round rather than just for a few days during the conference. Survey responses also indicate that members are enthusiastic and want to engage in more meaningful ways with the association but that a formal approach to keeping members interested and active all year (not just during the conference) is necessary.

Question Seven. As it relates to ALE's competition, participants do not really see ALE as having competitors. Participants noted that the International Leadership Association, for example, is a highly respected association but it is a larger entity and while it may have a broad reach and greater funding, it cannot necessarily offer the intimacy that ALE does when it comes to networking. Likewise, the Center for Creative Leadership (CCL) and the American Society of Training and Development (ASTD), now known as the Association of Talent Development (ATD), are also thought of as superb organizational and leadership entities, but each has niche different than ALE. 
Journal of Leadership Education DOI: 10.12806/V15/I1/A4 Volume 15 Issue 1 Application

\section{Discussion}

According to Franz (2011), the facilitation of focus groups is both a science and an art. The RDC is pleased with the success of Phase One of its action research project. The thoughts and opinions of participants in the 2014 focus groups have been, for the most part, confirmed by the data collected in the 2014 ALE member survey. In sum, it has been determined that simply knowing about ALE has not historically been reason enough to compel people to attend conferences or join the association. There is consensus that most join or become involved because of a specific event or based on the recommendation from a trusted member or colleague. Overall, focus group participants and survey respondents were complimentary of ALE's growth in recent years and with the quality of the annual conferences.

Even though the association has grown over the years, ALE members have expressed the need for ALE to promote the association and JOLE (as a product of the association's works) more. The value of the relationships that exist through ALE and the subsequent opportunities that have arisen as a result of networking at the annual conferences shows great promise.

The fact that ALE is not a large entity is not viewed as an impediment to progress. Indeed, ALE is large enough to have a significant impact. But, it is still small enough to fully support a tightly woven network of engaged scholars and practitioners.

\section{Conclusion}

Phase One of the RDC's action research project has revealed valuable insights. These insights have been shared with the ALE board of directors and the RDC is now implementing Phase Two of the action research project which involves addressing the issues deemed most critical in terms of supporting the association's strategic direction. Exploration of members' views will be continued in future focus groups or roundtable discussions at the next ALE conference.

The first priority for the RDC in supporting ALE is to secure funding, resources, talent, and technology for ALE produced webinars. The second priority is to explore the idea of regional chapters for ALE. The RDC has recruited ALE members with targeted expertise who will be developing a plan for launching a new series of webinars. In addition, members of the RDC will be hosting a round-table discussion at the 2015 conference for the purpose of gathering information from members about how they would like to structure regional chapters and what they feel the role of those chapters should be.

The RDC has been successful in creating an actionable plan for developing resources and in launching an action research project that can be adapted and used by other entities for a similar purpose. As leadership educators prepare students to lead in for-profit, nonprofit, and voluntary associations and organizations, they are challenged to provide students with leadership and management tools that will meet the unique needs of each type of organization. Leadership educators interested in expanding their program curriculum in this area may want to use this article as a case study or consider incorporating material from the reference section of this article into new or existing courses. 
Journal of Leadership Education DOI: 10.12806/V15/I1/A4 Volume 15 Issue 1 Application

For entities wishing to duplicate this project, the following steps are recommended: (a) form an RDC and select a chair person; (b) gather detailed information from the association's board of directors about the goals and objectives of the work to be done; (c) define expectations and parameters; (d) clarify roles and functions of committee members; (e) tailor the instruments that will be used for data collection to fit the needs of the association; (f) schedule focus groups and coordinate data collection at times and in places that will yield the greatest participation; and (g) analyze data and complete reports in a timely manner. It is our hope that by sharing phase one of this action research project, other entities will be able to model ALE's success and effectively grow their organizations.

\section{References}

Altrichter, H., Feldman, A., Posch, P., \& Somekh, B. (2013). Teachers investigate their work: An introduction to action research across the professions. New York, NY: Routledge.

Association of Leadership Educators (ALE). (2015). About ALE. Retrieved from: http://www.leadershipeducators.org/About

Andenoro, A. C., Allen, S. J., Haber-Curran, P., Jenkins, D. M., Sowcik, M., Dugan, J. P., \& Osteen, L. (2013). National Leadership Education research agenda 2013-2018:

Providing strategic direction for the field of leadership education. Retrieved from: http://leadershipeducators.org/ResearchAgenda.

Chiu, L. F. (2003). Transformational potential of focus group practice in participatory action research. Action Research, 1(2), 165-183.

Creswell, J. W. (1994). Research design: Qualitative and quantitative approaches. Thousand Oaks, CA: Sage Publications.

Franz, N. K. (2011). The unfocused focus group: Benefit or bane? The Qualitative Report, 16(5), 1380-1388.

Harris, M. (1998). Doing it their way: Organizational challenges for voluntary associations. Nonprofit and Voluntary Sector Quarterly, 27(2), 144-158.

Hall, P. D. (2006). A historical overview of philanthropy, voluntary associations, and nonprofit organizations in the United States, 1600-2000. The nonprofit sector: A research handbook, 2, 32-65.

Frumkin, P. (2006). Strategic giving: The art and science of philanthropy. Chicago, IL: University of Chicago Press.

Grudens-Schuck, N., Allen, B. L., \& Larson, K. (2004). Focus group fundamentals. [FactSheet]. Ames, IA: Iowa State University Extension. 
Journal of Leadership Education DOI: 10.12806/V15/I1/A4 Volume 15 Issue 1 Application

Krueger, R., \& Casey, M. (2009). Focus groups: A practical guide for applied research (4th ed.). Thousand Oaks, CA: Sage Publications.

Linville, D., Lambert-Shute, J., Fruhauf, C. A., \& Piercy, F. P. (2003). Using participatory focus groups of graduate students to improve academic departments: A case example. The Qualitative Report, 8(2), 210-223.

Razavi, S. H., \& Attarnezhad, O. (2013). Management of organizational innovation. International Journal of Business and Social Science, 4(1), 226-232.

Renz, D. O. (2004). An overview of nonprofit governance. Philanthropy in America. Santa Barbara, CA.: ABC-CLIO.

Reason, P., \& Bradbury, H. (Eds.). (2001). Handbook of action research: Participative inquiry and practice. London, UK: Sage Publications.

Richards, L., \& Morse, J.M. (2007). Readme first for a user's guide to qualitative methods $\left(2^{\text {nd }}\right.$ ed.). Thousand Oaks, CA: Sage Publications, Inc.

Tesch, R. (1990). Qualitative research: Analysis and software tools. New York, NY: Falmer.

\section{Author Biographies}

Donnette J. Noble, Ph.D., currently serves as an assistant professor of organizational leadership in the Evelyn T. Stone College of Professional Studies at Roosevelt University in Chicago. Dr. Noble received a Ph.D. from the University of Nebraska at Lincoln in human science with a specialization in leadership studies and she earned both her MA in management with a leadership emphasis and a dual-major BA in Public Administration and Organizational Communication from Doane College. Specializing in diversity and leadership, Dr. Noble has received multiple teaching and community service awards and is the recipient of multiple research grants and funded projects. Dr. Noble's passion for socially just leadership is reflected in her research and in her community service including work with at-risk youth, public and private school children, adult English-language learners, human rights agencies, and with a variety of programs that address poverty, food shortage, healthcare, homelessness, environmental concerns, and animal welfare.

Dr. Lyna Matesi teaches management, leadership, ethics and strategy at the University of Wisconsin-Stevens Point. Her passion is helping leaders and leadership teams maximize their capacity for success. She has served in leadership development, change management, and curriculum development roles at U.S. Cellular and in business planning, communication technology, and project management roles at Motorola. Dr. Matesi earned a BA in management and leadership from Judson University, an MA in change leadership and organizational renewal from Antioch University, and a Ph.D. in leadership studies from Gonzaga University. 
Jennifer Moss Breen, Ph.D., serves as an Associate Professor in Creighton University's Interdisciplinary Leadership Ed.D. program. Before joining Creighton University, Dr. Moss Breen served as the inaugural Director of Bellevue University's Human Capital Management Ph.D. program. Dr. Moss Breen earned her Ph.D. from the University of Nebraska (2006) in Leadership Studies. She currently serves as the Vice President of the Association of Leadership Educators and the Chair of the Business Leadership Member Interest Group for the International Leadership Association. Dr. Moss Breen currently teaches business courses within the Ed.D. program and conducts research in the areas of leader resilience, leader humility, knowledge sharing, leadership development, and medical school leadership education.

Robin Peiter Horstmeier, Ph.D., is the Founder and Owner of Horstmeier Consulting, LLC. Through her work with Horstmeier Consulting, she facilitates youth agricultural advocacy programs and mentors agricultural education students and teachers with various leadership programs for Missouri FFA. In addition, Dr. Horstmeier assists agricultural companies advance their work focused in STEM education and employee leadership. She also serves an Associate Teaching Professor in the Department of Human Development and Family Sciences at the University of Missouri-Columbia, where she teaches graduate courses in youth leadership development. Dr. Horstmeier's research examines leadership development and engagement in the context of youth, education and community. Dr. Horstmeier currently serves on the Association of Leadership Educators Board of Directors and is the Director of Resource Development.

Dennis M. Anderson, Ph.D., is Distinguished Professor of Education at Marshall University. His responsibilities include working with doctoral students in the Leadership Studies program and serving as the faculty advisor for the Leadership Specialist Masters for nonprofit organizations; the degree is wholly online. Prior to his return to the faculty, Dr. Anderson served in administrative positions at Appalachian State University, University of Southern California, Indiana University, University of Alabama, Arizona State University, and the West Virginia Graduate College. Dr. Anderson's research interests include higher education governance, fundraising management, and the history of the Shakers.

Stuart Allen, Ph.D., is an associate professor in the Organizational Leadership Department at Robert Morris University as well as a dissertation chair on Ed.D. Organizational Leadership and D.Sc. Information Systems and Communications programs. He conducts research on leadership pedagogy, higher education, posttraumatic stress disorder, organizational culture, and teaching with technology.

Leslie J. Pedigo serves as the Assistant Director of Leadership Education in the Office of Student Involvement at the University of Kentucky. In this role, she has created many of the programs she oversees, including two different leadership workshop series, a women's leadership retreat and year-long program, and a student organization focused on peer leadership education. Her passions lead her to specifically work with women's leadership and organizational leadership, allowing her to facilitate several student leadership conferences and present on new initiatives at national conferences. 